\title{
BMJ Open Post-operative patient-related risk factors for chronic pain after total knee replacement: a systematic review
}

\author{
Vikki Wylde, Andrew D Beswick, Jane Dennis, Rachael Gooberman-Hill
}

To cite: Wylde V, Beswick AD, Dennis J, et al. Postoperative patient-related risk factors for chronic pain after total knee replacement: a systematic review. BMJ Open 2017;7:e018105. doi:10.1136/ bmjopen-2017-018105

- Prepublication history and additional material for this paper are available online. To view these files, please visit the journal online (http://dx.doi org/10.1136/bmjopen-2017018105).

Received 6 June 2017 Revised 24 August 2017 Accepted 15 September 2017

CrossMark

Musculoskeletal Research Unit, Bristol Medical School, University of Bristol, Bristol, UK

Correspondence to

Dr Vikki Wylde;

v.wylde@bristol.ac.uk

\section{ABSTRACT}

Objective To identify postoperative patient-related risk factors for chronic pain after total knee replacement (TKR). Design The systematic review protocol was registered on the International Prospective Register of Systematic Reviews (CRD42016041374). MEDLINE, Embase and PsycINF0 were searched from inception to October 2016 with no language restrictions. Key articles were also tracked in the Institute for Scientific Information (ISI) Web of Science. Cohort studies evaluating the association between patient-related factors in the first 3 months postoperatively and pain at 6 months or longer after primary TKR surgery were included. Screening, data extraction and assessment of methodological quality were undertaken by two reviewers. The primary outcome was pain severity in the replaced knee measured with a patient-reported outcome measure at 6 months or longer after TKR. Secondary outcomes included adverse events and other aspects of pain recommended by the core outcome set for chronic pain after TKR.

Results After removal of duplicates, 16430 articles were screened, of which 805 were considered potentially relevant. After detailed evaluation of full-text articles, 14 studies with data from 1168 participants were included. Postoperative patient-related factors included acute pain (eight studies), function (five studies) and psychosocial factors (four studies). The included studies had diverse methods for assessment of potential risk factors and outcomes, and therefore narrative synthesis was conducted. For all postoperative factors, there was insufficient evidence to draw firm conclusions about the association with chronic pain after TKR. Selection bias was a potential risk for all studies, as none were reported to be conducted at multiple centres.

Conclusion This systematic review found insufficient evidence to draw firm conclusions about the association between any postoperative patient-related factors and chronic pain after TKR. Further high-quality research is required to provide a robust evidence base on postoperative risk factors, and inform the development and evaluation of targeted interventions to optimise patients' outcomes after TKR.

\section{INTRODUCTION}

Primary total knee replacement (TKR) is a common operation, with over 100000 operations performed in the UK in $2015,{ }^{12}$ and demand is projected to increase dramatically. ${ }^{3}$

\section{Strengths and limitations of this study}

This is the first systematic review of patientrelated risk factors for chronic pain after total knee replacement.

- Meta-analysis was not possible due to heterogeneity in the assessment of risk factors and outcomes.

- We did not include studies that used a composite pain and function measure to assess outcome.

Patients choose to have a TKR to relieve chronic pain and improve functional ability, ${ }^{4}$ but approximately $20 \%$ of patients experience chronic postsurgical pain, ${ }^{56}$ defined as pain present at 3 months after surgery. ${ }^{7}$ The impact of chronic pain after TKR is considerable and patients may struggle to cope and adjust to this pain. ${ }^{8}$ Provision of services for patients with chronic pain after TKR is patchy and inconsistent, ${ }^{9}$ with a lack of explicit access points. ${ }^{10}$ A systematic review identified that only one intervention has been evaluated for the management of this condition: a single intra-articular botulinum toxin injection. ${ }^{11}$

The identification of risk factors for chronic pain after TKR is a fundamental step in designing interventions to improve patient outcomes. Understanding the relevance of non-modifiable factors, such as sex and ethnicity, can help patients and clinicians work together to make informed decisions about TKR. Although some factors may not be modifiable, others may be amenable to intervention. Identification of modifiable patient-related risk factors is an important element in the development of interventions to improve outcomes after TKR. Previous systematic reviews have synthesised the literature on preoperative risk factors for chronic pain after TKR. ${ }^{12-15}$ These reviews have found evidence for a range of modifiable preoperative patient-related risk factors, including pain intensity, catastrophising, mental health and comorbidities. Preoperative interventions have largely focused on exercise and 
education and have shown little long-term postoperative benefit. ${ }^{15}$ Further interventions specifically targeting pain-related behaviours, such as cognitive-behavioural patient education and pain-coping skills training, are being evaluated. ${ }^{1617}$

While the potential value for preoperatively identifying at-risk patients and targeting them with appropriate interventions is clear, multivariable models have been found to have low predictive power, explaining less than $10 \%$ of the variability in chronic pain. ${ }^{18}$ An operation itself is an important risk factor for chronic pain, ${ }^{19}$ and factors relating to the operation and early recovery may be important risk factors. A risk index including presurgical variables and acute postsurgical pain had 'fair' predictive power for the development of chronic postsurgical pain across diverse surgery types. ${ }^{20}$ Therefore, in addition to evaluating preoperative risk factors, it is important to consider postsurgical factors that may limit rehabilitation and recovery, and be associated with chronic pain. If patients at risk of developing chronic pain could be identified in the early postoperative period, targeted interventions could be delivered, potentially as part of a comprehensive perioperative care package, to prevent the development of chronic pain. Although trials evaluating the effectiveness of early postoperative interventions on reducing chronic pain have been conducted, ${ }^{21-24}$ no systematic review has yet evaluated postoperative risk factors for chronic pain after TKR. Therefore, the aim of this systematic review was to identify early postoperative patient-related risk factors for chronic pain after TKR.

\section{METHODS}

\section{Protocol and registration}

The protocol was registered on the International Prospective Register of Systematic Reviews (PROSPERO) on 6 July 2016 (reference: CRD42016041374). Conduct and reporting of this systematic review adhere to recommendations from the Preferred Reporting Items for Systematic Reviews and Meta-Analyses ${ }^{25}$ (online supplementary appendix 1).

\section{Eligibility criteria}

Studies were eligible for inclusion in the review if they met the following criteria:

\section{Population}

Adults undergoing primary TKR predominantly for osteoarthritis: Studies that included patients with TKR combined with patients undergoing other orthopaedic procedures were included if separate results were available for patients with TKR.

\section{Exposure}

Postoperative patient-related risk factors measured in the first 3 months after surgery: Patients with exposure were those with a risk factor (categorical variable) or higher level of risk factor (continuous variable). The focus of this review was on patient-related risk factors with the potential for modification or use in targeting care, and therefore studies that assessed clinical risk factors (eg, length of stay, postoperative complications or radiographical measurements) or analgesic use were excluded.

\section{Comparator}

Patients with absence of risk factor (categorical variable) or lower level of risk factor (continuous variable).

\section{Outcome}

Severity of pain in the replaced knee measured with a patient-reported outcome measure at 6 months or longer after TKR surgery.

\section{Study design}

Cohort studies that have explored the relationships between factors measured in the first 3 months postoperative and longer term pain outcomes.

\section{Information sources and searches}

MEDLINE, Embase and PsycINFO were searched from inception to 17 October 2016. Searches were conducted by experienced systematic reviewers $(\mathrm{AB}$ and $\mathrm{JD})$ based on established design filters. ${ }^{26}$ The search strategy combined terms relating to study design (eg, cohort, epidemiological study) and population (eg, knee replacement, knee arthroplasty). Full search strategies are provided in online supplementary appendix 2. No language restrictions were applied. Searches were supplemented with hand-searching of reference lists and review articles, and key articles were tracked in the ISI Web of Science. Conference abstracts were excluded. ClinicalTrials.gov was searched on 18 August 2017 for ongoing observational studies and records screened in duplicate by two reviewers (JD and VW).

\section{Study selection and data extraction}

Bibliographical details of the articles identified were exported into EndNote X7 (Thomson Reuters) and duplicates removed. After an initial screening of titles and abstracts by one reviewer $(\mathrm{AB})$ to remove clearly irrelevant studies, titles and abstracts were screened in duplicate by two reviewers $(\mathrm{AB}$ and $\mathrm{VW})$. As recommended in the Cochrane Handbook, ${ }^{28}$ reviewers were 'over inclusive' at early stages and retained any potentially relevant studies. Full texts of all such reports were acquired and assessed for eligibility against the PICOS criteria in duplicate by two reviewers (AB and VW). Discrepancies were resolved in discussion with a third reviewer (JD). Data from articles that met the eligibility criteria were extracted into an Excel database by one reviewer (VW), with checking against source articles by a second reviewer (AB or JD). Extracted data comprised country, date, setting, population, participant demographics, study methodology including statistical analysis, risk factors, time to follow-up, losses to follow-up, joint-specific pain outcomes, variables included in multivariable analyses, and information relevant to assessment of study methodological quality. 
Where necessary, authors of studies were contacted for further information to enable judgements about eligibility and/or to provide unpublished outcome data relevant to the review. If data from patients with TKR were combined with patients undergoing other orthopaedic procedures, separate data for patients with TKR were requested. If a combined pain and function outcome was reported, such as the Oxford Knee Score or Western Ontario and McMaster Universities Osteoarthritis Index (WOMAC) score, separate pain-specific data were requested, for example, the Oxford Knee Score pain subscale or WOMAC Pain Scale.

\section{Outcomes}

The primary outcome was pain severity in the replaced knee measured with a patient-reported outcome measure at 6 months or longer after TKR. Chronic postsurgical pain is defined as pain present at 3 months after surgery $^{7}$; however, research has shown that most of the improvement in pain occurs in the first 3-6 months after TKR surgery. ${ }^{29-32}$ Therefore, 6 months postoperative was deemed an appropriate time point to assess chronic pain. Secondary outcomes included adverse events and other aspects of pain recommended by the core outcome set for chronic pain after TKR. ${ }^{33}$ These included pain interference with daily living, pain and physical functioning, temporal aspects of pain, pain description, emotional aspects of pain, use of pain medication and satisfaction with pain relief. No limits were placed on the tools used to measure these outcomes.

\section{Assessment of methodological quality of included studies}

The Newcastle-Ottawa Quality Assessment Scale ${ }^{34}$ and ROBINS-I tool ${ }^{35}$ are established tools for the assessment of risk of bias in randomised controlled trials and studies reporting non-randomised controlled comparisons. However, risk of bias assessment in systematic reviews of observational studies is less well established. The MINORs tool $^{36}$ has been developed; however, this is a summative checklist, and as such risks rating reporting rather than conduct. ${ }^{37}$ Therefore we developed a non-summative checklist for use in this review. This checklist consisted of four items to assess selection bias (inclusion of consecutive patients and representativeness), bias due to missing data (follow-up rates) and bias due to inadequate consideration of confounding (multivariable or univariable analysis). These items were informed by existing tools, including the MINORs, Newcastle-Ottawa Quality Assessment Scale and the ROBINS-I tool. Each item was rated as adequate, not adequate or not reported. Each individual item rating is reported, rather than an overall score. Ratings of methodological quality for included studies were conducted independently by two reviewers (VW and JD), and any discrepancies were resolved in discussion with a third reviewer $(\mathrm{AB})$.

\section{Data synthesis}

In the protocol, meta-analyses were planned if two or more studies assessed the same risk factor with suitable methodology. In comparing groups of patients with or without a risk factor, outcomes adjusted for baseline patient factors would be considered in preference to unadjusted outcomes, and the effect of non-adjustment would be explored in a subgroup analysis. If studies reported categorical pain outcomes, risk ratios would be used to summarise cohort studies and ORs for casecontrol studies. For risk factors reported as continuous variables, results of meta-analyses would be reported as mean differences or standardised mean differences, depending on the consistency of risk factor and outcome measures reported. We planned to explore the effect of non-adjustment for other variables in a subgroup analysis. Assessment of heterogeneity was planned using the $\chi^{2}$ and $\mathrm{I}^{2}$ statistic. The protocol stated that we would conduct sensitivity analyses on methodological quality assessment.

At analysis stage, opportunities for meta-analysis were limited by heterogeneity in the assessment of risk factors and outcomes. Therefore, we undertook a descriptive narrative analysis, in keeping with the approach recommended by the Cochrane Handbook. ${ }^{28}$

\section{RESULTS}

After removal of duplicates, 16430 articles were screened, of which 857 were considered potentially relevant. After detailed evaluation of full-text articles, 14 studies with data from 1613 participants were included ${ }^{38-51}$ (figure 1). The most common reasons for excluding potentially relevant studies were because patient-related factors were not assessed and follow-up after TKR surgery was less than 6 months.

\section{Study characteristics}

An overview of study characteristics is provided in table 1 .

Of the 14 included studies, three were from the UK, two each from Australia, USA and Spain, and one study from Belgium, Denmark, France, Portugal and Serbia. Thirteen studies were conducted at a single centre and one study did not report the number of centres. Eleven of the studies were cohort studies, two were randomised controlled trials retrospectively analysed as cohort studies and one was a case-control study with prospective data collection. Sample sizes ranged from 23 to 402, with a median of 115 participants. One study included a small number of patients undergoing unicompartmental knee replacement but was included in the review as $83 \%$ of participants had TKR. ${ }^{49}$ Follow-up assessments varied: four studies assessed outcomes at 6 months after TKR, five at 12 months and the remainder between 3 and 7 years postoperatively. Pain at follow-up was evaluated using the WOMAC Pain Scale ${ }^{52}$ (five studies), Numerical Rating Scale (NRS; three studies), Visual Analogue Scale (VAS; two studies), American Knee Society Score pain question ${ }^{53}$ (two studies), and Verbal Descriptor Scale (VDS; two studies). Secondary outcomes for the review relating to serious adverse events and other aspects of 

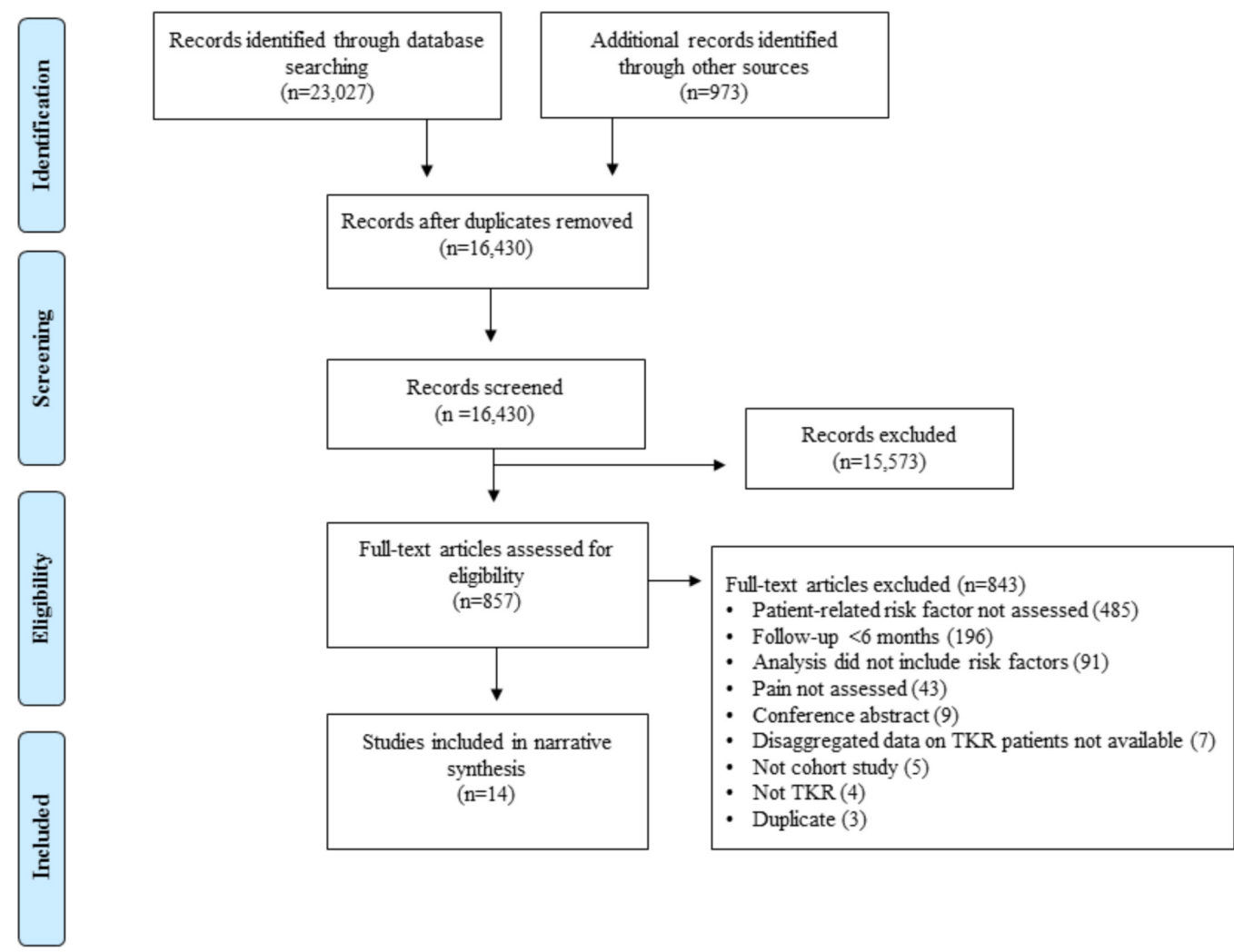

Figure 1 Systematic review flow diagram. TKR, total knee replacement.

Table 1 Characteristics of included studies

\begin{tabular}{|c|c|c|c|c|c|c|c|c|}
\hline Study & $\begin{array}{l}\text { Dates of } \\
\text { baseline } \\
\text { data } \\
\text { collection }\end{array}$ & $\begin{array}{l}\text { Study } \\
\text { design }\end{array}$ & Country & $\begin{array}{l}\text { Participants } \\
\text { recruited/at } \\
\text { final follow-up }\end{array}$ & $\begin{array}{l}\text { Mean/ } \\
\text { median age }\end{array}$ & Female (\%) & $\begin{array}{l}\text { Outcome } \\
\text { measure }\end{array}$ & $\begin{array}{l}\text { Duration of } \\
\text { follow-up }\end{array}$ \\
\hline Edwards et $a /^{39}$ & Not reported & Cohort & USA & 43 in analysis & 72 & 58 & VAS & 12 months \\
\hline Elson and Brenkel ${ }^{40}$ & 1995-1998 & $\begin{array}{l}\text { Case- } \\
\text { control }\end{array}$ & UK & $622 / 402$ knees & 69 & 54 & $\begin{array}{l}\text { AKSS pain } \\
\text { question }\end{array}$ & 5 years \\
\hline Núñez et $\left.a\right|^{42}$ & 2000-2001 & Cohort & Spain & $88 / 67$ & 75 & 81 & WOMAC pain & 3 years \\
\hline Núñez et al ${ }^{43}$ & 2000 & Cohort & Spain & $142 / 112$ & 67 & 77 & WOMAC pain & 7 years \\
\hline Phillips et $a l^{44}$ & 2009-2010 & Cohort & UK & $96 / 80$ & 71 & 56 & VAS & $\begin{array}{l}39-51 \\
\text { months }\end{array}$ \\
\hline Sayers et al ${ }^{47}$ & 2009-2012 & Cohort* & UK & $316 / 277$ & 69 & 53 & WOMAC pain & 12 months \\
\hline Stephens et $a l^{48}$ & Not reported & Cohort & USA & $71 / 63$ & 67 & 54 & WOMAC pain & 6 months \\
\hline Thomazeau et $a l^{49}$ & 2013 & Cohort & France & $109 / 104$ & 69 & 72 & NRS & 6 months \\
\hline Kocic et $\left.a\right|^{50}$ & 2007-2013 & Cohort & Serbia & $78 / 78$ & 68 & 76 & NRS & 6 months \\
\hline Veal et al ${ }^{51}$ & 2013 & Cohort & Australia & 23 in analysis & Not available & Not available & VDS & 12 months \\
\hline
\end{tabular}

${ }^{*}$ Retrospective analysis of randomised controlled trial data.

AKSS, American Knee Society Score; NRS, Numerical Rating Scale; VAS, Visual Analogue Scale; VDS, Verbal Descriptor Scale; WOMAC, Western Ontario and McMaster Universities Osteoarthritis Index. 
Table 2 Ratings of methodological quality for included studies

pain outcomes were infrequently reported and therefore not summarised.

\section{Assessment of methodological quality of included studies}

Ratings of methodological quality for the 14 included studies are provided in table 2. Eight studies reported that consecutive patients were recruited, eight studies followed up $>80 \%$ participants, and nine studies conducted multivariable analysis. All studies had issues relating to selection bias because none were reported as being conducted at multiple centres.

\section{Patient-related postoperative risk factors}

Patient-related postoperative risk factors were categorised into three groups: acute postoperative knee pain, knee function and psychosocial factors.

\section{Acute postoperative knee pain}

Eight studies including data from 737 participants evaluated the association between pain in the first 3 months after TKR and chronic pain (table 3). Timing of acute postoperative pain was classified as pain within the first postoperative week; pain between 1 and 2 weeks postoperatively; and pain from 2 weeks to 3 months. Pain as a risk factor was assessed using the VAS (three studies), VDS (two studies), NRS (two studies), WOMAC Pain Scale (one study) and PainDETECT (one study). Five studies conducted multivariable analysis, two studies conducted univariable analysis, and for one study no statistical analysis was performed as data were provided by authors on a small subset of patients with TKR.

\section{Pain severity on postoperative days 1-7}

Four studies with data from 491 participants evaluated whether pain severity in the first week after surgery was associated with chronic pain. ${ }^{414549}$ Two were at risk of bias due to missing data and one study was at risk of bias due to inadequate consideration of confounding. Methods used to assess pain included the $\mathrm{VDS}^{41} \mathrm{VAS}^{47}$ and NRS. ${ }^{454}$ Three studies found that more severe acute postoperative pain was associated with more severe pain at 6-12 months after TKR, ${ }^{41} 4749$ although in one study this association was attenuated completely after adjustment for preoperative pain. ${ }^{47}$ One study found no association between pain at 42 hours after surgery and the presence of chronic pain at 4-6 months. ${ }^{45}$

\section{Pain severity in postoperative days 8-14}

Three studies with data from 191 participants evaluated whether pain severity on postoperative days 8-14 was associated with chronic pain. ${ }^{384151}$ One study was at risk of bias due to missing data and two studies were at risk of bias due to inadequate consideration of confounding. Pain was assessed in two studies with the $\operatorname{VDS}^{4151}$ and in one with the WOMAC Pain Scale and VAS. ${ }^{38}$ Pain on postoperative day 8 and at 2 weeks was not found to be associated with chronic pain in two studies, ${ }^{3841}$ and descriptive data only were available for the study that evaluated pain on postoperative day $10 .{ }^{51}$ In the study with low risk of bias apart from with regard to representativeness, ${ }^{38}$ pain severity at 2 weeks was not found to be associated with pain at 6 months after TKR. 
Table 3 Studies evaluating acute postoperative knee pain as a risk factor for chronic pain after TKR

\begin{tabular}{|c|c|c|c|c|c|c|}
\hline Author and year & $\begin{array}{l}\text { Number } \\
\text { in } \\
\text { analysis }\end{array}$ & $\begin{array}{l}\text { Risk factor } \\
\text { measurement }\end{array}$ & Outcome(s) & $\begin{array}{l}\text { Univariable or } \\
\text { multivariable } \\
\text { analysis }\end{array}$ & Association & Results summary \\
\hline $\begin{array}{l}\text { Edwards et al, } \\
2009^{39}\end{array}$ & 43 & $\begin{array}{l}\text { Global pain VAS } \\
\text { at } 1 \text { month and } \\
3 \text { months }\end{array}$ & $\begin{array}{l}\text { Global pain } \\
\text { VAS at } 6 \text { and } \\
12 \text { months }\end{array}$ & $\begin{array}{l}\text { Multivariable } \\
\text { generalised estimating } \\
\text { equation model }\end{array}$ & Yes & $\begin{array}{l}\text { Global pain at a previous } \\
\text { time point was a predictor } \\
\text { of global pain at a future } \\
\text { time point (estimate }=0.43 \text {, } \\
S E=0.08, t=5.8, p<0.001 \text { ) }\end{array}$ \\
\hline \multirow[t]{3}{*}{$\begin{array}{l}\text { Crosbie et al, } \\
2010^{38}\end{array}$} & 100 & $\begin{array}{l}\text { WOMAC Pain } \\
\text { Scale at } 2 \text { weeks }\end{array}$ & $\begin{array}{l}\text { WOMAC } \\
\text { Pain Scale at } \\
6 \text { months }\end{array}$ & $\begin{array}{l}\text { Multivariable linear } \\
\text { regression }\end{array}$ & No & $\begin{array}{l}\text { Not significant, results not } \\
\text { reported }\end{array}$ \\
\hline & & $\begin{array}{l}\text { WOMAC pain at } \\
8 \text { weeks }\end{array}$ & & & Yes & $\begin{array}{l}\text { Beta } \\
\text { coefficient }=+0.25 \pm 0.07\end{array}$ \\
\hline & & VAS at 8 weeks & & & No & $\begin{array}{l}\text { Not significant, results not } \\
\text { reported }\end{array}$ \\
\hline $\begin{array}{l}\text { Pinto et al, } \\
2013^{45}\end{array}$ & 42 & NRS at 48 hours & $\begin{array}{l}\text { NRS at } \\
4-6 \text { months }\end{array}$ & $\begin{array}{l}\text { Hierarchical logistic } \\
\text { regression }\end{array}$ & No & $\begin{array}{l}\operatorname{Exp}(B)=0.998(95 \% \mathrm{Cl} \\
0.623 \text { to } 1.601), p=0.995\end{array}$ \\
\hline $\begin{array}{l}\text { Phillips et al, } \\
2014^{44}\end{array}$ & 80 & $\begin{array}{l}\text { PainDETECT at } \\
6 \text { weeks }\end{array}$ & $\begin{array}{l}\text { Pain VAS at } \\
39-51 \text { months }\end{array}$ & Univariable correlation & Yes & $\begin{array}{l}\text { PainDETECT at } 6 \text { weeks } \\
\text { correlated moderately with } \\
\text { VAS pain scores ( } r=0.53 \text { ). }\end{array}$ \\
\hline \multirow[t]{3}{*}{ Veal et al, $2015^{51}$} & 23 & $\begin{array}{l}\text { VDS for average } \\
\text { pain at } 10 \text { days }\end{array}$ & $\begin{array}{l}\text { VDS for } \\
\text { average pain at } \\
12 \text { months }\end{array}$ & $\begin{array}{l}\text { N/A-statistical } \\
\text { analysis inappropriate } \\
\text { as data provided by } \\
\text { authors on a small } \\
\text { subset of patients }\end{array}$ & $\mathrm{N} / \mathrm{A}$ & $\begin{array}{l}11 \text { patients had none/ } \\
\text { mild pain at } 10 \text { days, none } \\
\text { of these patients had } \\
\text { severe/moderate pain at } \\
12 \text { months. } \\
12 \text { patients had moderate/ } \\
\text { severe pain at } 10 \text { days, } \\
2 \text { of these patients had } \\
\text { moderate/severe at } \\
12 \text { months. }\end{array}$ \\
\hline & & $\begin{array}{l}\text { VDS for worst pain } \\
\text { at } 10 \text { days }\end{array}$ & $\begin{array}{l}\text { VDS for } \\
\text { worse pain at } \\
12 \text { months }\end{array}$ & & & $\begin{array}{l}2 \text { patients had none/mild } \\
\text { pain at } 10 \text { days, none } \\
\text { of these patients had } \\
\text { severe/moderate pain at } \\
12 \text { months. } \\
21 \text { patients had moderate/ } \\
\text { severe pain at } 10 \text { days, } \\
8 \text { of these patients had } \\
\text { moderate/severe at } \\
12 \text { months. }\end{array}$ \\
\hline & & $\begin{array}{l}\text { VDS for average } \\
\text { pain at } 6 \text { week }\end{array}$ & $\begin{array}{l}\text { VDS for } \\
\text { average pain at } \\
12 \text { months }\end{array}$ & & & $\begin{array}{l}17 \text { patients had none/mild } \\
\text { pain at } 6 \text { weeks, } 1 \text { of these } \\
\text { patients had moderate/ } \\
\text { severe pain at } 12 \text { months. } \\
6 \text { patients had moderate/ } \\
\text { severe pain at } 6 \text { weeks, } \\
1 \text { of these patients had } \\
\text { moderate/severe at } \\
12 \text { months. }\end{array}$ \\
\hline
\end{tabular}

Continued 
Table 3 Continued

\begin{tabular}{|c|c|c|c|c|c|c|}
\hline Author and year & $\begin{array}{l}\text { Number } \\
\text { in } \\
\text { analysis }\end{array}$ & $\begin{array}{l}\text { Risk factor } \\
\text { measurement }\end{array}$ & Outcome(s) & $\begin{array}{l}\text { Univariable or } \\
\text { multivariable } \\
\text { analysis }\end{array}$ & Association & Results summary \\
\hline & & $\begin{array}{l}\text { VDS for worst pain } \\
\text { at } 6 \text { weeks }\end{array}$ & $\begin{array}{l}\text { VDS for } \\
\text { worse pain at } \\
12 \text { months }\end{array}$ & & & $\begin{array}{l}9 \text { patients had none/ } \\
\text { mild pain at } 6 \text { weeks, } 1 \\
\text { of these patients had } \\
\text { severe/moderate pain at } \\
12 \text { months. } \\
14 \text { patients had moderate/ } \\
\text { severe pain at } 6 \text { weeks, } \\
7 \text { of these patients had } \\
\text { moderate/severe at } \\
12 \text { months. }\end{array}$ \\
\hline \multirow[t]{3}{*}{$\begin{array}{l}\text { Grosu et al, } \\
2016^{41}\end{array}$} & 68 & $\begin{array}{l}\text { VDS on days } 1,2 \\
\text { and } 3 \text { (cumulative } \\
\text { value of maximal } \\
\text { pain intensity) }\end{array}$ & $\begin{array}{l}\text { VDS at } \\
6 \text { months } \\
\text { VDS at } \\
12 \text { months }\end{array}$ & Univariable correlation & $\begin{array}{l}\text { Yes } \\
\text { Yes }\end{array}$ & $\begin{array}{l}r=0.350, p=0.009 \\
r=0.350, p=0.009\end{array}$ \\
\hline & & VDS on day 30 & $\begin{array}{l}\text { VDS at } \\
6 \text { months } \\
\text { VDS at } \\
12 \text { months }\end{array}$ & & $\begin{array}{l}\text { Yes } \\
\text { No }\end{array}$ & $\begin{array}{l}r=0.310, p=0.013 \\
\text { Not significant, results not } \\
\text { reported }\end{array}$ \\
\hline & & VDS at 3 months & $\begin{array}{l}\text { VDS at } \\
6 \text { months } \\
\text { VDS at } \\
12 \text { months }\end{array}$ & & $\begin{array}{l}\text { No } \\
\text { No }\end{array}$ & $\begin{array}{l}\text { Not significant, results not } \\
\text { reported } \\
\text { Not significant, results not } \\
\text { reported }\end{array}$ \\
\hline $\begin{array}{l}\text { Sayers et al, } \\
2016^{47}\end{array}$ & 277 & $\begin{array}{l}\text { VAS for pain on } \\
\text { rest on days } 1,2 \\
\text { and } 3 \text { (combined) }\end{array}$ & $\begin{array}{l}\text { WOMAC pain } \\
\text { at } 12 \text { months }\end{array}$ & $\begin{array}{l}\text { Multivariable structural } \\
\text { equation modelling }\end{array}$ & Yes & $\begin{array}{l}\text { Beta }=0.222, \mathrm{SE}=0.058, \\
95 \% \mathrm{Cl} 0.109 \text { to } 0.336, \\
\mathrm{p}=0.0001 \\
\text { When preoperative } \\
\text { pain added: beta }=0.09, \\
95 \% \mathrm{Cl}-0.09 \text { to } 0.27, \\
p=0.332\end{array}$ \\
\hline $\begin{array}{l}\text { Thomazeau et al, } \\
2016^{49}\end{array}$ & 104 & NRS on days 1-4 & $\begin{array}{l}\text { NRS at } \\
6 \text { months }\end{array}$ & $\begin{array}{l}\text { Multivariate logistic } \\
\text { regression }\end{array}$ & Yes & $\begin{array}{l}\text { Patients with high-intensity } \\
\text { acute postoperative pain } \\
\text { (defined through latent } \\
\text { class growth analysis) } \\
\text { were more likely to have } \\
\text { pain at } 6 \text { months than } \\
\text { patients with low-intensity } \\
\text { acute postoperative pain } \\
\text { (OR=4.23, } 95 \% \mathrm{Cl} 1.39 \text { to } \\
12.88, p=0.011) \text {. }\end{array}$ \\
\hline
\end{tabular}

N/A, not applicable; NRS, Numerical Rating Scale; TKR, total knee replacement; VAS, Visual Analogue Scale; VDS, Verbal Descriptor Scale; WOMAC, Western Ontario and McMaster Universities Osteoarthritis Index.

Pain severity between 2 weeks and 3 months postoperatively

Five studies with data from 314 participants evaluated whether pain severity between 2 weeks and 3 months postoperatively was associated with chronic pain after
TKR. ${ }^{38} 39414451$ Two studies were at risk of bias due to missing data and three studies were at risk of bias due to inadequate consideration of confounding. Methods to assess pain were the WOMAC Pain Scale, ${ }^{38}$ VAS $^{38} 3944$ 
and VDS. ${ }^{41}{ }^{51}$ In one study with risk of bias associated only with conduct at a single centre, pain severity at 8 weeks postoperatively was found to be associated with pain at 6 months postoperatively when assessed with the WOMAC but not the VAS. ${ }^{38}$ In one study with univariable analysis, pain severity assessed on day 30 was found to be associated with pain severity at 6 months but not 12 months after TKR. ${ }^{41}$ The same study found that pain at 3 months postoperatively was not associated with pain severity at 6 months and 12 months postoperatively. ${ }^{41}$ In another study, neuropathic pain at 6 weeks postoperatively was found to be moderately associated with pain at 39-51 months after surgery. ${ }^{44}$ In one study, there was no difference in pain at 12 months in patients with different average pain levels at 6 weeks. ${ }^{51}$ However considering 'worst' pain, $7 / 14$ patients with moderate to severe pain at 6 weeks reported moderate to severe pain at 12 months compared with $1 / 9$ patients with none or mild pain at 6 weeks. A study that assessed global pain and night pain at 1 month and 3 months postoperatively found that they were associated with global pain and night pain, respectively, at a future time point $(6$ months and 12 months). ${ }^{39}$

\section{Knee function}

Five studies including data from 835 participants evaluated the association between postoperative knee function and chronic pain after TKR (table 4). Three studies were at risk of bias due to missing data and one study was at risk of bias due to inadequate consideration of confounding. Assessment of knee function varied and included range of motion, ambulatory status, WOMAC function, $6 \mathrm{~min}$ walk test and stair ascent speed.

Four studies including data from 735 participants evaluated whether function at hospital discharge was associated with chronic pain after TKR. ${ }^{40} 42436$ Two of these studies assessed range of motion ${ }^{4046}$ and two assessed ambulatory status at discharge ${ }^{42}{ }^{43}$; none found an association. One study, at low risk of bias except inclusion of a single centre, with 100 patients evaluated whether function at 2 weeks and 8 weeks, assessed using three different methods, was associated with WOMAC pain scores at 6 months postoperatively. ${ }^{38}$ This study found that WOMAC function score at 2 weeks, but not 8 weeks, was associated with chronic pain; 6 min walk test at both 2 weeks and 8 weeks was associated with chronic pain; stair ascent speed at 2 and 8 weeks was not associated with chronic pain.

Table 4 Studies evaluating postoperative knee function as a risk factor for chronic pain after TKR

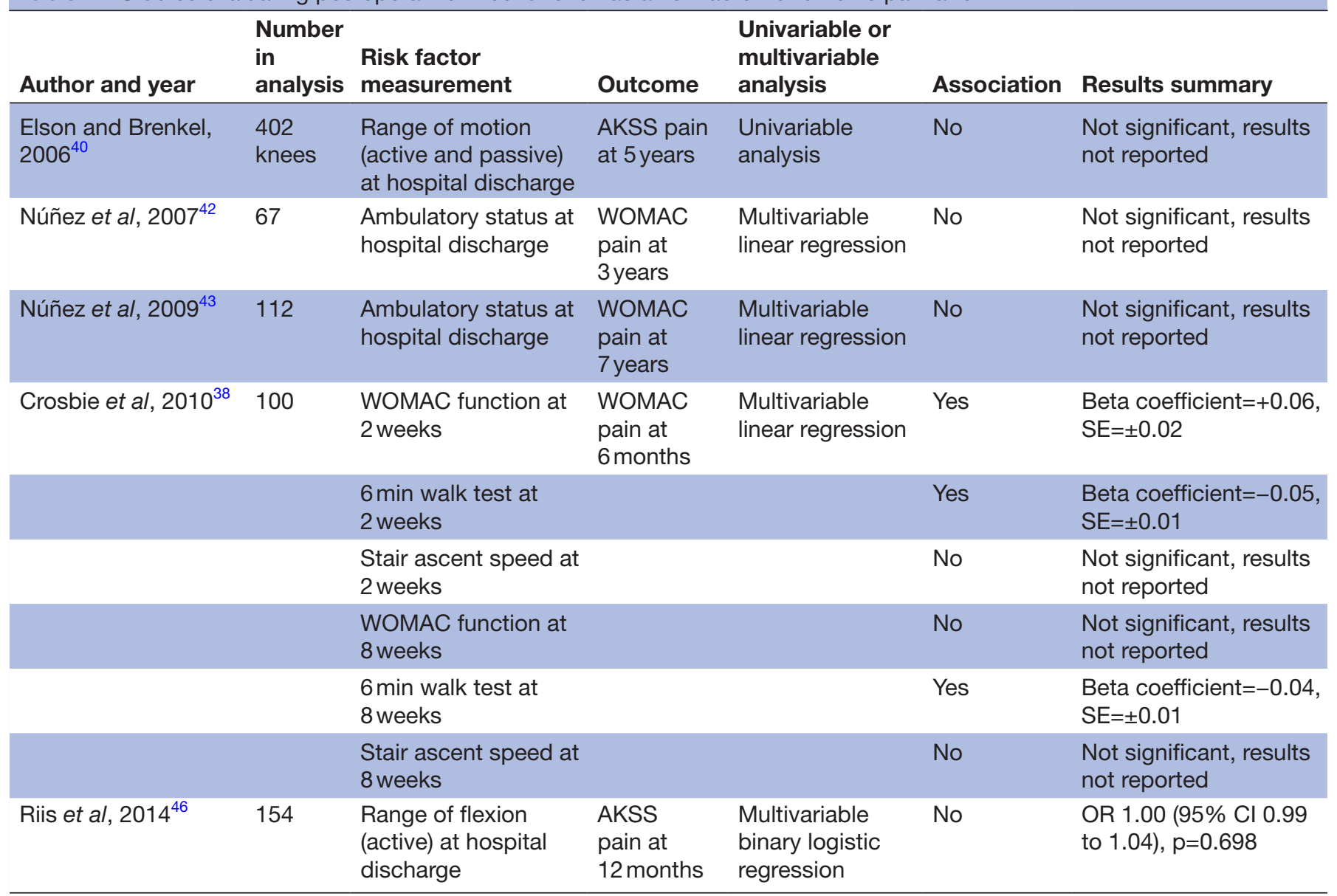

AKSS, American Knee Society Score; TKR, total knee replacement; WOMAC, Western Ontario and McMaster Universities Osteoarthritis Index. 


\section{Psychosocial factors}

Four studies including data from 226 participants evaluated the association between postoperative psychological factors and chronic pain after TKR (table 5). Two studies were at risk of bias due to missing data and one study was at risk of bias due to inadequate consideration of confounding. Risk factors assessed included catastrophising, depression, social support, coping skills, fear of movement and anxiety. In one study, catastrophising at a previous time point was a risk factor for night pain, but not global pain, at a future time point. ${ }^{39}$ In the same study, depression was found to be a risk factor for global pain but not night pain. Another study assessing risk factors at 6 weeks postoperatively found that perceived positive social support was associated with less chronic pain, negative social support with more chronic pain, and no association between coping and pain at 6 months after TKR. ${ }^{48}$ Patients with a high fear of movement at 2 weeks postoperatively reported more pain at 6 months than those with a low fear of movement. ${ }^{50}$ Greater anxiety at 48 hours after surgery was found to be associated with a higher risk of having a pain score of $>3$ on the NRS at 4-6 months after TKR. ${ }^{45}$

\section{Ongoing studies}

Searches of ClinicalTrials.gov identified five ongoing studies that are collecting data on patient-related postoperative risk factors and pain outcomes at 6 months or longer after TKR. An overview of these studies is provided in online supplementary appendix 3.

\section{DISCUSSION}

This is the first systematic review to evaluate postoperative patient-related risk factors for chronic pain after TKR. Fourteen cohort studies were identified which evaluated the association between patient-related factors measured in the first 3 months postoperatively and pain severity measured with a patient-reported outcome measure at 6 months or longer after primary TKR. Postoperative factors assessed included pain (eight studies), function (five studies) and psychosocial factors (four studies).

For all postoperative patient-related factors, there was insufficient evidence to draw firm conclusions on the association with chronic pain after TKR. When reviewing observational cohort studies, it is essential to consider issues that may introduce bias and lead to potentially misleading results and their interpretation. The key issues relate to generalisability, incomplete follow-up and accounting for confounding factors. Regarding generalisability, findings from single-centre and multicentre studies can differ, ${ }^{54}$ and one potential factor contributing to this difference is the recruitment of a more homogeneous population in single-centre studies. The population may be highly selected and therefore have limited validity external to the study setting. Losses to follow-up represent another cause of bias as patients who do not complete longer term assessments may have poorer outcomes. ${ }^{556}$ In this review, six studies had data on $<80 \%$ participants at follow-up. The methodological quality of five studies was limited by the lack of multivariable analysis to minimise the impact of potential confounding on results. In studies with no risk of bias other than patient selection, there was a suggestion that chronic pain was associated with increased acute postoperative pain during the hospital stay. ${ }^{47}$ However, in one of these studies, a comprehensive assessment of pain relationships over time suggested that the association was largely explained by preoperative pain. ${ }^{47}$ For later pain assessments, one study did not identify consistent associations between postoperative pain and chronic pain. ${ }^{38}$

This review has strengths and weaknesses that should be considered when interpreting the results. While our search terms were broad to identify cohort studies that involved patients with TKR, three studies were identified through methods other than the main searches. This is a recognised issue in the identification of observational studies $^{57}$ and highlights the importance in bibliographical databases of appropriate indexing and use of keywords. It is possible that studies including general orthopaedic or surgical populations may have included patients with TKR, and these may not have been identified. However, when these studies were identified, we contacted authors and data for patients with TKR were provided for two studies. ${ }^{451}$ The primary outcome of interest in this review was pain at 6 months or longer after TKR, and therefore we did not include studies that used a composite pain and function measure to assess outcome, for example the total Oxford Knee Score ${ }^{58}$ or WOMAC. ${ }^{52}$ This is because when such composite measures are reported without any separation of pain from function, it is not possible to use the scores to assess pain per se. Preoperative risk factors for postoperative pain and functional limitations are different, ${ }^{18}{ }^{59}$ and therefore it is important to assess pain and function as distinct outcomes. Separate pain and function scores can be calculated for the most commonly used patient-reported outcome measures, the WOMAC $^{60}$ and the Oxford Knee Score, ${ }^{61}$ and future studies would benefit from analysing these outcomes separately. Research on postoperative risk factors is limited by heterogeneity in how and when risk factors and outcomes are assessed. If greater standardisation could be achieved, such as through the implementation of core outcome sets, ${ }^{33}$ future systematic reviews may be able to pool data in meta-analysis to provide evidence for postoperative patient-related risk factors for chronic pain after TKR.

Much of the research evaluating risk factors for outcomes after TKR has focused on the preoperative period rather than the period after surgery. ${ }^{12}$ Numerous preoperative patient-related factors and their association to chronic pain have been evaluated, including knee pain severity and duration, pain at other sites, comorbidities, function, depression, social support, anxiety, fear of movement, pessimism and quality of life. ${ }^{12}$ In comparison, our review found that the current extent of research into postoperative risk factors is narrow, and 


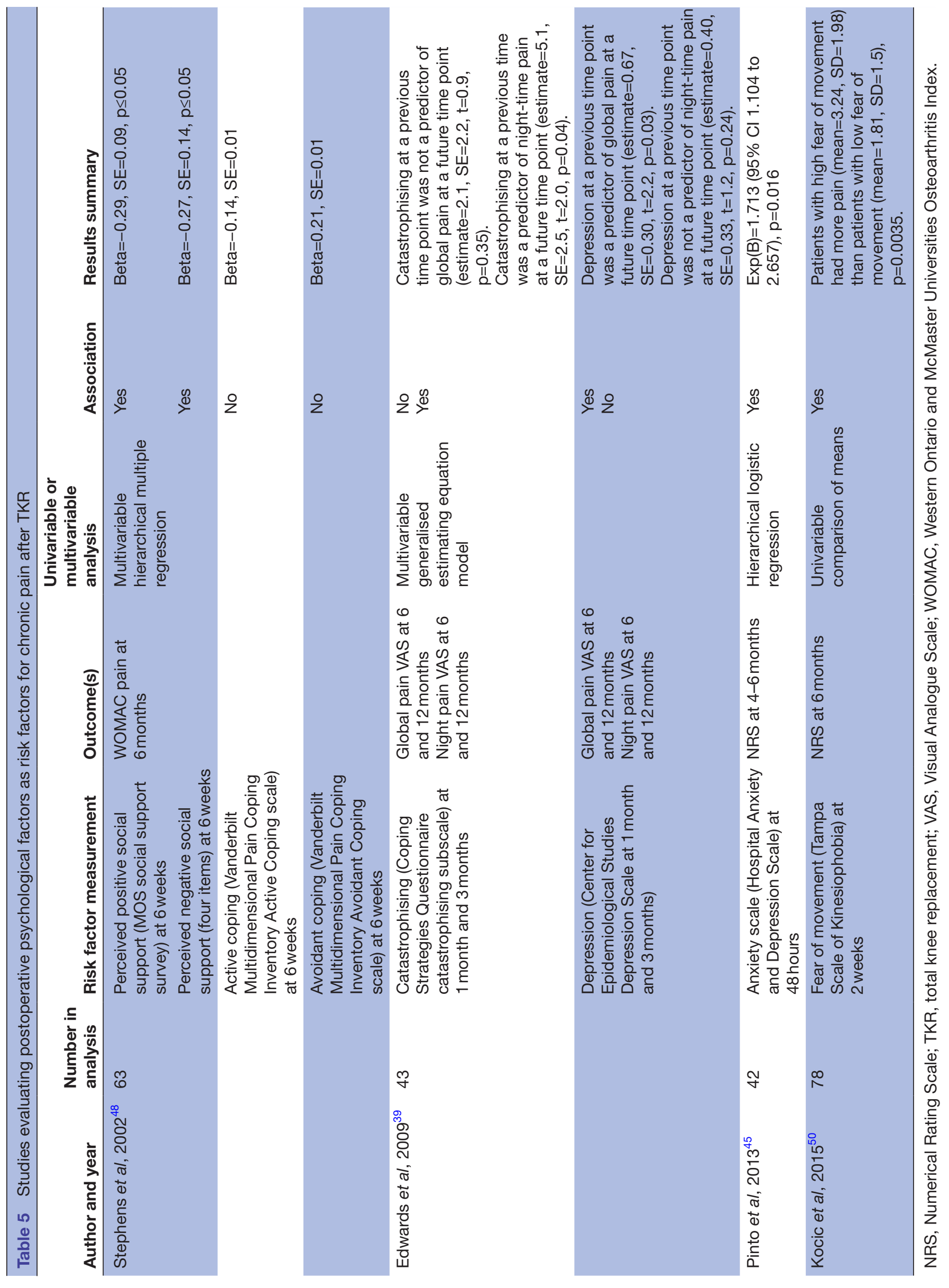


further research is needed. Searches of ClinicalTrials.gov found that a number of studies are ongoing in this field, suggesting the evidence base will continue to grow and develop. Assessing potential postoperative risk factors is important as some factors may be more associated with outcome when measured in the postoperative period, rather than in the preoperative period. ${ }^{62}$ Prediction of chronic postsurgical pain has been found to be strongest when assessing both preoperative and postoperative risk factors. ${ }^{20}$ Factors specific to the postoperative recovery period, such as acute postoperative pain, and factors that span the perioperative period, such as anxiety, have the potential to influence outcomes. Identification of both preoperative and postoperative risk factors could inform the development of comprehensive care packages to improve outcomes.

Despite the lack of sufficient evidence about postoperative risk factors, research has evaluated whether early postoperative interventions improve longer term outcomes after TKR. The long-term effects of pharmacological interventions to reduce pain severity in the early postoperative period have been evaluated, both in patients undergoing TKR and other surgical procedures. ${ }^{21}{ }^{22}$ While effective at reducing acute postoperative pain, numerous perioperative pharmacotherapies are not effective at preventing chronic postsurgical pain. Similarly, outpatient physiotherapy interventions to improve early postoperative function have little effect on long-term pain. ${ }^{23}{ }^{24}$ This may be because acute postoperative pain and functional limitations are not risk factors for chronic pain after TKR, or it may be that these interventions require evaluation in trials that are focused on high-risk patients. However, before evaluation of such stratified models of care is possible, more research is needed to identify postoperative patient-related risk factors for chronic pain after TKR.

In conclusion, this systematic review found insufficient evidence to draw conclusions about the association between any postoperative patient-related factor and chronic pain after TKR. To complement this research, systematic reviews are ongoing to evaluate the effectiveness of preoperative, perioperative and postoperative interventions in preventing chronic pain after TKR (PROSPERO reference CRD42017041382). Further highquality research is required to provide robust evidence on postoperative risk factors, and inform the development and evaluation of targeted interventions to optimise patients' outcomes after TKR.

Acknowledgements We would like to thank all the study authors who took the time to reply to our requests for further clarification or additional data.

Contributors All authors contributed to the concept and design of the study. AB, JD and VW contributed to the acquisition and analysis of data. VW drafted the article, and $A B, J D$ and $R G-H$ revised it critically for important intellectual content. VW and $A B$ take responsibility for the integrity of the work as a whole, from inception to finished article.

Funding This article presents independent research funded by the National Institute for Health Research (NIHR) under its Programme Grants for Applied Research (RP-PG-0613-20001). The views expressed are those of the authors and not necessarily those of the NHS, the NIHR or the Department of Health. The funder had no role in the study design, collection, analysis and interpretation of data; in the writing of the manuscript; or in the decision to submit the manuscript for publication.

Competing interests None declared.

Provenance and peer review Not commissioned; externally peer reviewed.

Data sharing statement No additional data are available.

Open Access This is an Open Access article distributed in accordance with the terms of the Creative Commons Attribution (CC BY 4.0) license, which permits others to distribute, remix, adapt and build upon this work, for commercial use, provided the original work is properly cited. See: http://creativecommons.org/ licenses/by/4.0/

C Article author(s) (or their employer(s) unless otherwise stated in the text of the article) 2017. All rights reserved. No commercial use is permitted unless otherwise expressly granted.

\section{REFERENCES}

1. National Joint Registry for England, Wales. Northern Ireland andthe Isle of Man.13th Annual Report. Hemel Hempstead: NJR Centre, 2016.

2. NHS National Services Scotland. Scottish arthroplasty project: biennial report 2016. Scotland: NHS National Services Scotland, 2016.

3. Maradit Kremers H, Larson DR, Crowson CS, et al. Prevalence of total hip and knee replacement in the US. J Bone Joint Surg Am 2015;97:1386-97.

4. Scott CE, Bugler KE, Clement ND, et al. Patient expectations of arthroplasty of the hip and knee. J Bone Joint Surg $\mathrm{Br}$ 2012;94:974-81.

5. Beswick AD, Wylde V, Gooberman-Hill R, et al. What proportion of patients report long-term pain after total hip or knee replacement for osteoarthritis? A systematic review of prospective studies in unselected patients. BMJ Open 2012;2:e000435.

6. Wylde V, Hewlett S, Learmonth ID, et al. Persistent pain after joint replacement: prevalence, sensory qualities, and postoperative determinants. Pain 2011;152:566-72.

7. Werner MU, Kongsgaard UE. Defining persistent post-surgical pain: is an update required? $\mathrm{Br} J$ Anaesth 2014;113:1-4.

8. Jeffery AE, Wylde V, Blom AW, et al. "It's there and I'm stuck with it": patients' experiences of chronic pain following total knee replacement surgery. Arthritis Care Res 2011;63:286-92.

9. Wylde V, Mackichan DS, Gooberman-Hill R. Service provision for patients with chronic post-surgical pain after total knee replacement: an evaluation of current practice. J Pain Manag 2014;7:147-54.

10. MacKichan F, Wylde V, Gooberman-Hill R. Pathways through care for long-term pain after knee replacement: a qualitative study with healthcare professionals. Musculoskeletal Care 2015:127-38.

11. Beswick AD, Wylde V, Gooberman-Hill R. Interventions for the prediction and management of chronic postsurgical pain after total knee replacement: systematic review of randomised controlled trials. BMJ Open 2015;5:e007387.

12. Lewis GN, Rice DA, McNair PJ, et al. Predictors of persistent pain after total knee arthroplasty: a systematic review and meta-analysis. Br J Anaesth 2015;114:551-61.

13. Baert IA, Lluch E, Mulder T, et al. Does pre-surgical central modulation of pain influence outcome after total knee replacement? A systematic review. Osteoarthritis Cartilage 2016;24:213-23.

14. Hernández C, Díaz-Heredia J, Berraquero ML, et al. Pre-operative Predictive Factors of Post-operative Pain in Patients With Hip or Knee Arthroplasty: A Systematic Review. Reumatol Clin 2015;11:361-80.

15. Blom AW, Artz N, Beswick AD, et al. Improving patients' experience and outcome of total joint replacement: the RESTORE programme. UK: NIHR Journals Library Southampton, 2016.

16. Birch S, Stilling M, Mechlenburg I, et al. Effectiveness of a physiotherapist delivered cognitive-behavioral patient education for patients who undergoes operation for total knee arthroplasty: a protocol of a randomized controlled trial. BMC Musculoskelet Disord 2017;18:116.

17. Riddle DL, Keefe FJ, Ang D, et al. A phase III randomized three-arm trial of physical therapist delivered pain coping skills training for patients with total knee arthroplasty: the KASTPain protocol. BMC Musculoskelet Disord 2012;13:149.

18. Judge A, Arden NK, Cooper C, et al. Predictors of outcomes of total knee replacement surgery. Rheumatology 2012;51:1804-13. 
19. Macrae WA. Chronic post-surgical pain: 10 years on. Br J Anaesth 2008;101:77-86.

20. Althaus A, Hinrichs-Rocker A, Chapman R, et al. Development of a risk index for the prediction of chronic post-surgical pain. Eur J Pain 2012;16:901-10.

21. Wylde V, Lenguerrand E, Gooberman-Hill R, et al. Effect of local anaesthetic infiltration on chronic postsurgical pain after total hip and knee replacement: the APEX randomised controlled trials. Pain 2015;156:1161-70.

22. Chaparro LE, Smith SA, Moore RA, et al. Pharmacotherapy for the prevention of chronic pain after surgery in adults. Cochrane Database Syst Rev 2013:CD008307.

23. Artz N, Elvers KT, Lowe CM, et al. Effectiveness of physiotherapy exercise following total knee replacement: systematic review and meta-analysis. BMC Musculoskelet Disord 2015;16:15.

24. Fransen M, Nairn L, Bridgett L, et al. Post-acute rehabilitation after total knee replacement: a multicenter randomized clinical trial comparing long-term outcomes. Arthritis Care Res 2017;69:192-200.

25. Moher D, Liberati A, Tetzlaff J, et al. Preferred reporting items for systematic reviews and meta-analyses: the PRISMA statement. BMJ 2009;339:b2535.

26. Marcano Belisario J, Tudor Car L, Reeves T, et al. Search strategies to identify observational studies in MEDLINE and EMBASE (Protocol). Cochrane Database Syst Rev 2013:MR000041.

27. Scottish Intercollegiate Guidelines Network. Search filters. http:// www.sign.ac.uk/methodology/filters.html\#obs (accesssed Sep 2016).

28. Higgins J, Green SE. The Cochrane Collaboration. Cochrane handbook for systematic reviews of interventions version 5.1.0, 2011 www.cochrane-handbook.org

29. Lenguerrand E, Wylde V, Gooberman-Hill R, et al. Trajectories of pain and function after primary hip and knee arthroplasty: the ADAPT cohort study. PLoS One 2016;11:e0149306.

30. Davis AM, Perruccio AV, Ibrahim S, et al. The trajectory of recovery and the inter-relationships of symptoms, activity and participation in the first year following total hip and knee replacement. Osteoarthritis Cartilage 2011;19:1413-21.

31. Halket A, Stratford PW, Kennedy DM, et al. Using hierarchical linear modeling to explore predictors of pain after total hip and knee arthroplasty as a consequence of osteoarthritis. J Arthroplasty 2010;25:254-62.

32. Wylde V, Dixon S, Miller L, et al. 5 Year outcomes and survivorship of the triathlon total knee replacement: a cohort study. Acta Orthop Belg. In Press.

33. Wylde V, MacKichan F, Bruce J, et al. Assessment of chronic post-surgical pain after knee replacement: development of a core outcome set. Eur J Pain 2015;19:611-20.

34. Wells G, Shea B, O'Connell D, et al. The Newcastle-Ottawa Scale (NOS) for assessing the quality if nonrandomized studies in metaanalyses. 2017 http://www.ohri.ca/programs/clinical_epidemiology/ oxford.asp

35. Sterne JA, Hernán MA, Reeves BC, et al. ROBINS-I: a tool for assessing risk of bias in non-randomised studies of interventions. BMJ 2016;355:i4919.

36. Slim K, Nini E, Forestier D, et al. Methodological index for nonrandomized studies (minors): development and validation of a new instrument. ANZ J Surg 2003;73:712-6.

37. Jüni $P$, Witschi $A$, Bloch $R$, et al. The hazards of scoring the quality of clinical trials for meta-analysis. JAMA 1999;282:1054-60.

38. Crosbie J, Naylor J, Harmer A, et al. Predictors of functional ambulation and patient perception following total knee replacement and short-term rehabilitation. Disabil Rehabil 2010;32:1088-98.

39. Edwards RR, Haythornthwaite JA, Smith MT, et al. Catastrophizing and depressive symptoms as prospective predictors of outcomes following total knee replacement. Pain Res Manag 2009;14:307-11.

40. Elson DW, Brenkel IJ. Predicting pain after total knee arthroplasty. $J$ Arthroplasty 2006;21:1047-53.

41. Grosu I, Thienpont E, De Kock M, et al. Dynamic view of postoperative pain evolution after total knee arthroplasty: a prospective observational study. Minerva Anestesiol 2016;82:274-83.

42. Núñez M, Núñez E, del Val JL, Luis del Val J, et al. Health-related quality of life in patients with osteoarthritis after total knee replacement: factors influencing outcomes at 36 months of followup. Osteoarthritis Cartilage 2007;15:1001-7.

43. Núñez M, Lozano L, Núñez E, et al. Total knee replacement and health-related quality of life: factors influencing long-term outcomes. Arthritis Rheum 2009;61:1062-9.

44. Phillips JR, Hopwood B, Arthur C, et al. The natural history of pain and neuropathic pain after knee replacement: a prospective cohort study of the point prevalence of pain and neuropathic pain to a minimum three-year follow-up. Bone Joint J 2014;96-B:1227-33.

45. Pinto PR, Mclntyre T, Ferrero R, et al. Risk factors for moderate and severe persistent pain in patients undergoing total knee and hip arthroplasty: a prospective predictive study. PLoS One 2013;8:e73917.

46. Riis A, Rathleff MS, Jensen MB, et al. Low grading of the severity of knee osteoarthritis pre-operatively is associated with a lower functional level after total knee replacement: a prospective cohor study with 12 months' follow-up. Bone Joint J 2014;96-B:1498-502.

47. Sayers A, Wylde V, Lenguerrand E, et al. Rest Pain and MovementEvoked Pain as Unique Constructs in Hip and Knee Replacements. Arthritis Care Res 2016;68:237-45.

48. Stephens MA, Druley JA, Zautra AJ. Older adults' recovery from surgery for osteoarthritis of the knee: psychosocial resources and constraints as predictors of outcomes. Health Psychol 2002;21:377-83.

49. Thomazeau J, Rouquette A, Martinez V, et al. Predictive factors of chronic post-surgical pain at 6 months following knee replacement: Influence of postoperative pain trajectory and genetics. Pain Physician 2016;19:E729-E741.

50. Kocic M, Stankovic A, Lazovic M, et al. Influence of fear of movement on total knee arthroplasty outcome. Ann Ital Chir 2015;86:148-55.

51. Veal FC, Bereznicki LR, Thompson AJ, et al. Subacute pain as a predictor of long-term pain following orthopedic surgery: an australian prospective 12 month observational cohort study. Medicine 2015;94:e1498.

52. Bellamy N, Buchanan WW, Goldsmith $\mathrm{CH}$, et al. Validation study of WOMAC: a health status instrument for measuring clinically important patient relevant outcomes to antirheumatic drug therapy in patients with osteoarthritis of the hip or knee. J Rheumatol 1988;15:1833-40.

53. Insall JN, Dorr LD, Scott RD, et al. Rationale of the Knee Society clinical rating system. Clin Orthop Relat Res 1989:13???14-14.

54. Bafeta A, Dechartres A, Trinquart L, et al. Impact of single centre status on estimates of intervention effects in trials with continuous outcomes: meta-epidemiological study. BMJ 2012;344:e813.

55. Murray DW, Britton AR, Bulstrode CJ. Loss to follow-up matters. $J$ Bone Joint Surg Br 1997;79:254-7.

56. Kim J, Lonner JH, Nelson CL, et al. Response Bias: effect on outcomes evaluation by mail surveys after total knee arthroplasty. $J$ Bone Joint Surg Am 2004;86-A:15-21.

57. Stroup DF, Berlin JA, Morton SC, et al. Meta-analysis of observational studies in epidemiology: a proposal for reporting. Meta-analysis Of Observational Studies in Epidemiology (MOOSE) group. JAMA 2000;283:2008-12.

58. Dawson J, Fitzpatrick R, Murray D, et al. Questionnaire on the perceptions of patients about total knee replacement. $J$ Bone Joint Surg Br 1998;80:63-9.

59. Lopez-Olivo MA, Landon GC, Siff SJ, et al. Psychosocial determinants of outcomes in knee replacement. Ann Rheum Dis 2011;70:1775-81.

60. Bellamy N. WOMAC: a 20-year experiential review of a patientcentered self-reported health status questionnaire. $J$ Rheumatol 2002;29:2473-6.

61. Harris K, Dawson J, Doll H, et al. Can pain and function be distinguished in the Oxford Knee Score in a meaningful way? An exploratory and confirmatory factor analysis. Qual Life Res 2013:22:2561-8.

62. van den Akker-Scheek I, Stevens M, Groothoff JW, et al. Preoperative or postoperative self-efficacy: which is a better predictor of outcome after total hip or knee arthroplasty? Patient Educ Couns 2007;66:92-9. 